\title{
Seventy-two-hour emergency department revisits among adults with chronic diseases: a Saudi Arabian study
}

This article was published in the following Dove Press journal: Therapeutics and Clinical Risk Management

\author{
Anwar E Ahmed 1,2 \\ Doaa A AlBuraikan ${ }^{2}$ \\ Hend R Almazroa ${ }^{2}$ \\ Manair N Alrajhi² \\ Bashayr I ALMuqbil2 \\ Monirah A Albaijan' \\ Majid A Alsalamah ${ }^{2}$ \\ Hamdan AL-Jahdali ${ }^{1,2}$
}

'King Abdullah International Medical Research Center (KAIMRC), Riyadh, Saudi Arabia; ${ }^{2}$ King Saud bin Abdulaziz University for Health Sciences,

National Guard Health Affairs, Riyadh, Saudi Arabia
Correspondence: Anwar E Ahmed College of Public Health and Health Informatics, King Saud Bin Abdulaziz University for Health Sciences, MC 2350, PO Box 22490 Riyadh, II426, Saudi Arabia

Email ahmeda5@vcu.edu
Background: Despite the increase in adult emergency department (ED) utilization in Saudi Arabia, no studies have evaluated the 72-hour revisits. This study estimates the rate of 72-hour ED revisits and identifies its reasons and predictive factors among adults with chronic diseases.

Patients and methods: A hospital-based retrospective study that included 24,206 ED discharges for adults with chronic diseases at the adult ED of King Abdulaziz Medical City, Riyadh between September 13, 2015 and July 29, 2017 was performed. We extracted data on demographic information, reasons for ED visits/revisits, health insurance coverage, weekend ED arrival, and mortality.

Results: A sample of 24,206 ED discharges for 19,697 adults with at least one chronic disease was included in the analysis. The rate of 72-hour revisits in this study population was high: 3,144/24,206 (13\%) had the first revisit and 319/3,144 (10.1\%) had the second ED revisit within 72 hours. Diseases of the circulatory (19\%) and genitourinary (15.8\%) systems were the major reasons for the first ED revisit. The adjusted relative rate (aRR) of 72-hour ED revisits was higher in adults with chronic diseases and aged $\geq 60$ years ( $\mathrm{aRR}=1.360,95 \% \mathrm{CI}: 1.41-1.83 ; P=0.001$ ), patients of female gender $(\mathrm{aRR}=1.24,95 \% \mathrm{CI}: 1.09-1.41 ; P=0.001)$, patients with health insurance coverage $(\mathrm{aRR}=4.23,95 \% \mathrm{CI}: 2.60-6.90 ; P=0.001)$, patients arriving to $\mathrm{ED}$ on a weekend $(\mathrm{aRR}=2.13,95 \%$ CI: $1.03-4.41 ; P=0.041$ ), and new patients (aRR=1.47, 95\% CI: $1.25-1.73 ; P=0.001$ ).

Conclusion: The rate of 72-hour revisits is high among adults with chronic diseases. Advancing age, female gender, health insurance coverage, weekend ED arrival, and new patients are the important predictive factors of the high rate of 72 -hour revisits. Continuous quality assessment and monitoring of factors related to patients are needed to reduce the frequency of early ED revisits after discharge.

Keywords: 72-hour ED revisits, emergency department, KAMC, Saudi Arabia

\section{Introduction}

Overcrowding the emergency department (ED) is a widespread practice in Saudi Arabia. ${ }^{1}$ It not only represents a large burden on the Saudi health care system, but also is a barrier for receiving timely services for urgent care, ${ }^{2,3}$ and poses great risks for cluster viral infections such as Middle East Respiratory Syndrome Coronavirus. ${ }^{3}$ An ED revisit within 72 hours has been used as a benchmark to improve the health care quality of services, work efficiency, and to ensure patient safety. ${ }^{4-6}$

The ED revisit within 72 hours has been widely reported in earlier studies, and its rate depends on the chronic disease status and the cultural background. ${ }^{6-12}$ The rates of 72-hour ED revisits may depend on age, ${ }^{10,11}$ gender, ${ }^{10,13}$ disease categories, ${ }^{6-8,12}$ medical errors, ${ }^{7,8}$ patients, ${ }^{7}$ and doctors. ${ }^{7}$ Although data regarding ED revisits within 72 hours can be used to implement changes and modifications to improve the electronic medical 
record database, the rate of revisits to the ED within 72 hours has not been documented among adults with chronic diseases in Saudi Arabia, particularly in our center.

This study may serve as a benchmark for the quality of urgent care in our center to reduce 72-hour revisits to the ED and improve medical care in adults with chronic diseases. The study may serve as a foundation of future studies on a national scale to assess Saudi health care system responsiveness.

This study aims to evaluate the rate, reasons, and predictive factors of the high rate of 72-hour ED revisits among adults with chronic diseases at King Abdulaziz Medical City Hospital-Riyadh (KAMC-RD), Saudi Arabia. The study aimed to evaluate the relationship between the rate of 72-hour ED revisits and age, gender, health insurance status, and day of arrival in adults with chronic diseases at KAMC-RD.

\section{Patients and methods}

A hospital-based retrospective study was performed on the study subjects with chronic diseases who presented to the adult ED at KAMC-RD, which is the largest university hospital in Saudi Arabia.

We included all adults of age $\geq 18$ years with at least one chronic disease who were discharged from the ED of KAMC-RD between September 13, 2015 and July 29, 2017. In 2015, KAMC-RD implemented an electronic medical record-integrated database: BESTCare. We focused on the most common chronic diseases that were set as nation health priorities for treatment and prevention, such as diabetes, heart disease, asthma, hypertension, and cancer. ${ }^{14}$

The following data were retrieved from the BESTCare database: age, gender, causes of ED initial visit, the date/time of ED arrival, whether a patient had a health insurance coverage, new patient (yes/no), and whether the day of ED arrival was on a weekend. Patients' ages were divided into two groups (age group $<60$ and $\geq 60$ years). A previous study forms the basis for this classification because ED revisit was found to be common in the population aged $\geq 60+$ years. ${ }^{10}$ A new patient was defined as the first presentation of an individual to receive ED services.

The primary outcome of the study was the number of ED revisits within 72 hours recorded for each ED discharge $(0,1,2$, etc). The unit of analysis was the number of ED discharges. The cause of each ED revisit was collected. We used the International Statistical Classification of Diseases and Related Health Problems, Tenth Revision, Australian modification (version 2010) code, chapters I-XXII, to map and classify the cause of ED visits/revisits.

\section{Statistical analysis}

We used IBM SPSS Statistics for Windows, version 25 (IBM Corp., Armonk, NY, USA) for data analyses. Categorical variables were presented as counts and percentages, and continuous variables as mean and SD. A univariate negative binomial regression model was used to estimate the unadjusted relative rate (RR) and to identify the factors associated with the high rate of ED revisits within 72 hours of ED discharge. A multivariate negative binomial regression model was used to estimate the adjusted relative rate (aRR) and to identify the independent factors associated with the high rate of ED revisits within 72 hours of ED discharge. The strength of the relationship was assessed by RR and aRR with $95 \%$ CI. A threshold of $P$-value $\leq 0.05$ was used to determine the presence of statistical significance.

\section{Ethics approval and consent to participate}

The study received ethical approval from the Ethical Review Committee at the Ministry of National Guard - Health Affairs, approval \#RC17/081/R. Due to the retrospective design of the study, consent from patients to review their medical records was not required by the Ethical Review Committee at the Ministry of National Guard - Health Affairs. Data were de-identified to protect the privacy and confidentiality of patient information.

\section{Results}

A sample of 24,206 ED discharges for 19,697 adults with at least one chronic disease was included in the analysis; $3,144 / 24,206$ (13\%) had their first revisit, of which 319 (10.1\%) had a second ED revisit within 72 hours after ED discharge. Table 1 illustrates the sample and clinical characteristics. The mean age of the sample was $56.2 \pm 17.2$ years, with an age range between 18 and 111.5 years.

The most common reasons for the initial ED visit among adults with chronic diseases were diseases of the circulatory system $(36 \%)$, genitourinary system $(31.6 \%)$, various symptoms $(4.7 \%)$, respiratory system $(4.2 \%)$, digestive system (4.1\%), and endocrine system (3.5\%).

The most common reasons for the first ED revisit within 72 hours after the initial visit were diseases of the circulatory system (19\%), issues with the genitourinary system $(15.8 \%)$, various symptoms $(15.7 \%)$, issues with the respiratory system $(12.4 \%)$, issues with the digestive system (6.5\%), and issues with the endocrine system $(5.7 \%)$.

The most common reasons for the second ED revisit within 72 hours after the initial visit were various symptoms 
Table I Characteristics and outcomes of adults with chronic diseases who visited/revisited ED within 72 hours (24,206 ED discharges)

\begin{tabular}{llll}
\hline Variable & Levels & $\mathbf{n}$ & $\%$ \\
\hline Elderly ( $\geq 60$ years) & Yes & 8,646 & 35.8 \\
& No & 11,050 & 45.6 \\
& Missing & 4,510 & 18.6 \\
Gender & Male & 8,911 & 36.8 \\
& Female & 10,786 & 44.6 \\
& Missing & 4,509 & 18.6 \\
Health insurance coverage & Yes & 18,731 & 77.4 \\
& No & 966 & 4 \\
Weekend ED arrival & Missing & 4,509 & 18.6 \\
& Yes & 1,200 & 5 \\
& No & 18,496 & 76.4 \\
New patient & Missing & 4,510 & 18.6 \\
& Yes & 2,111 & 8.7 \\
Initial ED discharges $(\mathbf{N}=\mathbf{2 4 , 2 0 6 )}$ & No & 12,541 & 51.8 \\
Had the first revisit within 72 hours & Missing & 9,554 & 39.5 \\
& No & 21,062 & 87 \\
Had the second revisit within 72 hours & Yes & 3,144 & 13 \\
& No & 2,825 & 89.9 \\
& Yes & 319 & 10.1 \\
\hline Abbra & & &
\end{tabular}

Abbreviation: ED, emergency department.

(24.5\%), issues with the genitourinary system (17.2\%), pregnancy and childbirth (8.5\%), issues with the digestive system $(7.2 \%)$, issues with the circulatory system $(7.2 \%)$, external causes $(6.9 \%)$, and issues with the musculoskeletal system (5.6\%), as shown in Figure 1.

Unadjusted analysis of negative binomial (Table 2) revealed that adults with chronic diseases and aged $\geq 60$ years ( $\mathrm{RR}=1.58,95 \% \mathrm{CI}: 1.46-1.70 ; P=0.001)$, having health insurance coverage ( $\mathrm{RR}=3.85,95 \% \mathrm{CI}: 2.74-5.38 ; P=0.001$ ), having weekend $\mathrm{ED}$ arrival (RR=2.41, 95\% CI: 2.15-2.69; $P=0.001)$, new patients $(\mathrm{RR}=1.42,95 \% \mathrm{CI}: 1.23-1.65$;
$P=0.001)$, and initial causes for ED visits, pregnancy and childbirth (RR=1.33, 95\% CI: $1.04-1.71 ; P=0.026)$ increased the rate of revisits to the ED within 72 hours after ED discharge.

Adjusted analysis of negative binomial (Table 2) revealed that adults with chronic diseases and aged $\geq 60$ years (aRR $=1.60,95 \%$ CI: $1.41-1.83 ; P=0.008)$, female gender (aRR=1.24, 95\% CI: 1.09-1.41; $P=0.001)$, having health insurance coverage $(\mathrm{aRR}=4.23,95 \% \mathrm{CI}: 2.60-6.90$; $P=0.001)$, having weekend $\mathrm{ED}$ arrival (aRR $=2.13,95 \% \mathrm{CI}$ : $1.03-4.41 ; P=0.041)$, and new patients $(\mathrm{aRR}=1.47,95 \% \mathrm{CI}$ : $1.25-1.73 ; P=0.001)$ increased the rate of revisits to the ED within 72 hours after ED discharge.

\section{Discussion}

The study evaluated the rate of frequent revisits to the ED within 72 hours by adults with chronic diseases presenting to the largest university hospital ED in Riyadh, Saudi Arabia between September 13, 2015 and July 29, 2017. Of the 24,206 ED discharges, $13 \%$ had the first ED revisit after ED discharge. This is the high rate of early ED revisit, and this trend must be explored further in a prospective study by assessing ED admission and discharge strategies.

The rate of ED revisit within 72 hours after ED discharge was considerably higher than the findings in several earlier studies that evaluated 72-hour ED revisits in the general adult populations. ${ }^{7,8,10,15,16}$ The rates of 72-hour return to the ED were as follows: the USA $0.5 \%,{ }^{16}$ Taiwan $1.32 \%-2.38 \%,{ }^{8}$ Singapore $2.93 \%,{ }^{10}$ the USA $4.2 \%,{ }^{15}$ and Taiwan $5.47 \% .{ }^{7}$ However, the rate of ED revisits within 72 hours after ED discharge was widely reported in a recent multi-site study in the USA. ${ }^{17}$ Our rate falls within the site-specific range from $1.1 \%$ to $15.2 \%$ that was reported from 31 hospitals in the

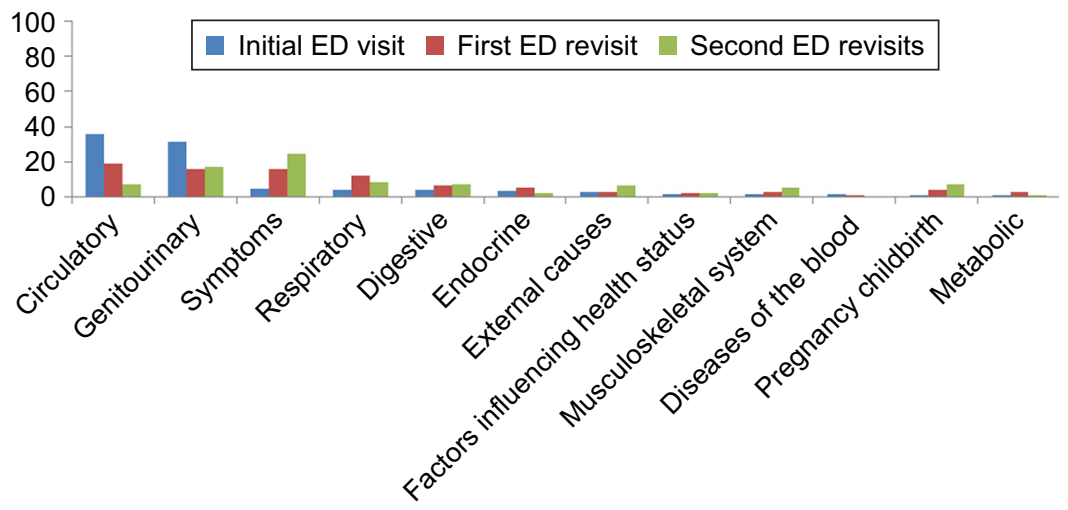

Figure I The most common reasons of ED visits and 72-hour revisits.

Abbreviation: ED, emergency department. 
Table 2 Unadjusted and adjusted relative rates of revisits to ED within 72 hours of discharge in adults with chronic diseases (24,206 ED discharges)

\begin{tabular}{|c|c|c|c|c|c|c|c|c|}
\hline \multirow[t]{3}{*}{ Factor } & \multicolumn{4}{|c|}{ Bivariate analysis } & \multicolumn{4}{|c|}{ Multivariate analysis } \\
\hline & \multicolumn{4}{|c|}{ 95\% Cl for RR } & \multicolumn{4}{|c|}{ 95\% CI for aRR } \\
\hline & $P$-value & $\mathbf{R R}$ & Lower & Upper & $P$-value & aRR & Lower & Upper \\
\hline Elderly ( $\geq 60$ years) & $0.00 \mathrm{I}^{\mathrm{a}}$ & 1.58 & 1.46 & 1.70 & $0.00 I^{a}$ & 1.60 & 1.41 & 1.83 \\
\hline Female & 0.461 & 1.03 & 0.95 & I.II & $0.00 \mathrm{I}^{\mathrm{a}}$ & $\mathrm{I} .24$ & 1.09 & $1.4 \mathrm{I}$ \\
\hline Health insurance coverage & $0.00 \mathrm{I}^{\mathrm{a}}$ & 3.85 & 2.76 & 5.38 & $0.00 I^{a}$ & 4.23 & 2.60 & 6.90 \\
\hline Weekend ED arrival & $0.00 \mathrm{I}^{\mathrm{a}}$ & 2.41 & 2.15 & 2.69 & $0.04 I^{\mathrm{a}}$ & 2.13 & 1.03 & $4.4 I$ \\
\hline New patient & $0.00 \mathrm{I}^{\mathrm{a}}$ & 1.42 & 1.23 & 1.65 & $0.00 \mathrm{I}^{\mathrm{a}}$ & 1.47 & 1.25 & 1.73 \\
\hline Blood & 0.103 & 0.81 & 0.63 & $\mathrm{I} .04$ & 0.382 & 2.47 & 0.33 & 18.67 \\
\hline Cause of morbidity or mortality & 0.087 & 0.72 & 0.50 & 1.05 & 0.753 & $\mathrm{I} .4 \mathrm{I}$ & 0.17 & 11.89 \\
\hline Kidney disease & 0.052 & 0.68 & 0.46 & 1.00 & 0.362 & 2.60 & 0.33 & 20.43 \\
\hline Circulatory & $0.00 \mathrm{I}^{\mathrm{a}}$ & 0.50 & 0.44 & 0.58 & 0.743 & 1.40 & 0.19 & 10.27 \\
\hline Digestive & 0.052 & 0.83 & 0.68 & 1.00 & 0.478 & 2.09 & 0.27 & 15.88 \\
\hline Ear & $0.047^{\mathrm{a}}$ & 0.57 & 0.33 & 0.99 & 0.726 & 1.51 & 0.15 & 15.17 \\
\hline Endocrine & $0.00 \mathrm{I}^{\mathrm{a}}$ & 0.56 & 0.45 & 0.71 & 0.675 & 1.54 & 0.20 & 11.65 \\
\hline External causes & $0.00 \mathrm{I}^{\mathrm{a}}$ & 0.58 & 0.45 & 0.73 & 0.793 & 1.35 & 0.14 & 12.55 \\
\hline Eye adnexa & $0.022^{\mathrm{a}}$ & 0.62 & 0.41 & 0.93 & 0.939 & 1.09 & 0.12 & 10.14 \\
\hline Factors influencing health & $0.00 \mathrm{I}^{\mathrm{a}}$ & 0.50 & 0.37 & 0.68 & 0.750 & $\mathrm{I} .40$ & 0.18 & 11.07 \\
\hline Genitourinary & 0.353 & 0.94 & 0.82 & 1.07 & 0.296 & 2.90 & 0.39 & 21.30 \\
\hline Infectious & 0.701 & 1.12 & 0.64 & 1.95 & 0.517 & 2.57 & 0.15 & 44.57 \\
\hline Metabolic & 0.055 & 0.71 & 0.50 & 1.01 & 0.674 & 0.61 & 0.06 & 6.07 \\
\hline Musculoskeletal system & $0.00 \mathrm{I}^{\mathrm{a}}$ & 0.59 & 0.44 & 0.78 & 0.176 & 0.14 & 0.01 & 2.38 \\
\hline Neoplasm & 0.121 & $\mathrm{I} .40$ & 0.91 & 2.15 & 0.152 & 5.24 & 0.54 & 50.49 \\
\hline Nervous & 0.246 & 0.74 & 0.45 & 1.23 & 0.333 & 3.39 & 0.29 & 40.03 \\
\hline Pregnancy childbirth & $0.026^{a}$ & 1.33 & 1.04 & I.7I & 0.110 & 5.90 & 0.67 & 51.96 \\
\hline Respiratory & $0.013^{\mathrm{a}}$ & 0.78 & 0.64 & 0.95 & 0.754 & 0.70 & 0.08 & 6.48 \\
\hline Skin subcutaneous & 0.459 & 0.84 & 0.53 & $\mathrm{I} .34$ & 1.000 & 1.00 & 0.06 & 16.74 \\
\hline Others & $0.017^{a}$ & 0.60 & 0.40 & 0.91 & 0.285 & 3.14 & 0.39 & 25.51 \\
\hline
\end{tabular}

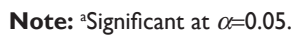

Abbreviations: aRR, adjusted relative risk; ED, emergency department; GU, genitourinary; MSK, musculoskeletal system; RR, relative risk.

USA. ${ }^{17}$ The high rate of ED revisits within 72 hours after ED discharge in our center could be attributed to several factors related to patient, doctor, and hospital database system issues. Continuous quality assessment and monitoring of these factors may enhance the quality of ED care.

In adults with chronic diseases, several factors were found to be associated with a higher rate of ED revisits within 72 hours of discharge. For instance, the rate of ED revisits was $24 \%$ higher for females than for males. In conflict with our study, male gender was reported to be a positive predictor for ED revisits within 72 hours of discharge. ${ }^{10,13,18}$ It may not be possible to compare our findings with those of these studies due to methodological issues, since Ganti et a ${ }^{13}$ studied specific population, patients with mild traumatic brain injury. Ahmed et a ${ }^{19}$ studied patients with sickle cell disease. Although the bivariate results showed gender was not associated with ED revisits within 72 hours of discharge, in the multivariate results, a higher risk of ED revisits was found among patients of female gender. This discrepancy between the bivariate and multivariate analyses could be attributed to the adjustment of other factors such as elderly patient, new patient, weekend ED arrival, and health insurance coverage.

We found a higher rate of ED revisits within 72 hours of discharge by adults with chronic diseases and aged $\geq 60$ years, consistent with the report of Chan et $\mathrm{al}^{10}$ and contrary to the report of Ganti et al,,$^{13}$ where an ED revisit was not associated with age. The high rate of ED revisits in adults with chronic diseases and aged $\geq 60$ years may be due to an increased risk of developing a number of chronic diseases, which may cause unnecessary ED visits rather than seeking medical services at the primary care clinics. A study is needed in future to evaluate the access to primary care clinics and the reasons for avoiding ED visits and revisits in this population.

Unlike other studies, ${ }^{13,17}$ we found the rate of ED revisits within 72 hours of ED discharge was four times high in patients with health insurance coverage than in patients with no health insurance coverage. A number of studies have documented that there was more ED utilization in individuals 
with Medicaid or health insurance coverage than in uninsured or privately insured individuals. ${ }^{20-22}$

Moreover, adults with chronic diseases who visited the ED on weekends had a high rate of ED revisit within 72 hours of ED discharge. A study from Nebraska, USA, showed that the ED utilization rate was more on weekends than on workdays. ${ }^{23}$

The main limitation of the study is lack of several confounding factors such as patient-related reasons for ED visits and the mode of arrival to the ED. The study was a retrospective study based on a single clinical center rather than multiple clinical centers, and a prospective evaluation of 72 hours of ED revisits. The authors were not able to track ED revisits reported in another clinical center. Other confounding factors were not gathered, such as details on the mode of arrival and the number of chronic diseases. Despite these limitations, this is the first study investigating the rate of ED revisits within 72 hours of ED discharge among adults with chronic diseases in Saudi Arabia. The study utilized a sample of 24,206 ED visits and accounted for multiple revisits within 72 hours of ED discharge for each patient.

\section{Conclusion}

The rate of 72-hour revisits among adults with chronic diseases is high in our center. Advancing age, female gender, health insurance coverage, weekend ED arrival, and new patients are predictive factors of a high rate of 72-hour revisits. Continuous quality assessment and monitoring of factors related to the patient are needed to reduce the frequency of early ED revisits after discharge. Further interventional studies are warranted to assess modifiable factors that could be beneficial to enhance ED quality care.

\section{Acknowledgments}

The authors gratefully acknowledge the Saudi Ministry of Health and the Ministry of National Guard Health Affairs (NGHA) for approving this research project.

\section{Disclosure}

The authors report no conflicts of interest in this work.

\section{References}

1. Rehmani R, Norain A. Trends in emergency department utilization in a hospital in the Eastern region of Saudi Arabia. Saudi Med J. 2007; 28(2):236-240.

2. Khalifa M, Zabani I. Reducing emergency department crowding: evidence based strategies. Stud Health Technol Inform. 2016;226:67.

3. Hastings DL, Tokars JI, Abdel Aziz IZ, et al. Outbreak of Middle East Respiratory Syndrome at Tertiary Care Hospital, Jeddah, Saudi Arabia, 2014. Emerg Infect Dis. 2016;22(5):794-801.
4. Lawrence LM, Jenkins CA, Zhou C, Givens TG. The effect of diagnosisspecific computerized discharge instructions on 72-hour return visits to the pediatric emergency department. Pediatr Emerg Care. 2009;25(11):733-738.

5. Cheng SY, Wang HT, Lee CW, et al. The characteristics and prognostic predictors of unplanned hospital admission within 72 hours after ED discharge. Am J Emerg Med. 2013;31(10):1490-1494.

6. Tsai IT, Sun CK, Chang CS, Lee KH, Liang CY, Hsu CW. Characteristics and outcomes of patients with emergency department revisits within 72 hours and subsequent admission to the intensive care unit. Ci Ji Yi Xue Za Zhi. 2016;28(4):151-156.

7. Wu CL, Wang FT, Chiang YC, et al. Unplanned emergency department revisits within 72 hours to a secondary teaching referral hospital in Taiwan. J Emerg Med. 2010;38(4):512-517.

8. Liaw SJ, Bullard MJ, Hu PM, Chen JC, Liao HC. Rates and causes of emergency department revisits within 72 hours. J Formos Med Assoc. 1999;98(6):422-425.

9. Adekoya N. Patients seen in emergency departments who had a prior visit within the previous $72 \mathrm{~h}$-National Hospital Ambulatory Medical Care Survey, 2002. Public Health. 2005;119(10):914-918.

10. Chan AH, Ho SF, Fook-Chong SM, Lian SW, Liu N, Ong ME. Characteristics of patients who made a return visit within 72 hours to the emergency department of a Singapore tertiary hospital. Singapore Med J. 2016;57(6):301-306.

11. Goh GL, Huang P, Kong MC, Chew SP, Ganapathy S. Unplanned reattendances at the paediatric emergency department within 72 hours: a oneyear experience in KKH. Singapore Med J. 2016;57(6):307-313.

12. Ahmed A, Alburaikan D, Almuqbil B, Aljohi W, Alanazi W, Alrasheed B. Readmissions and emergency department visits after bariatric surgery at Saudi Arabian hospital: the rates, reasons, and risk factors. Obes Facts. 2017;10(5):432-443.

13. Ganti L, Conroy LM, Bodhit A, et al. Understanding why patients return to the emergency department after mild traumatic brain injury within 72 hours. West J Emerg Med. 2015;16(3):481-485.

14. Al-Turki YA. Overview of chronic diseases in the Kingdom of Saudi Arabia. Saudi Med J. 2000;21(5):499-500.

15. Ngai KM, Grudzen CR, Lee R, Tong VY, Richardson LD, Fernandez A. The association between limited english proficiency and unplanned emergency department revisit within 72 hours. Ann Emerg Med. 2016;68(2):213-221.

16. Abualenain J, Frohna WJ, Smith M, et al. The prevalence of quality issues and adverse outcomes among 72-hour return admissions in the emergency department. J Emerg Med. 2013;45(2):281-288.

17. Shy BD, Kim EY, Genes NG, et al. Increased identification of emergency department 72-hour returns using multihospital health information exchange. Acad Emerg Med. 2016;23(5):645-649.

18. Cho CS, Shapiro DJ, Cabana MD, Maselli JH, Hersh AL. A national depiction of children with return visits to the emergency department within 72 hours, 2001-2007. Pediatr Emerg Care. 2012;28(7): 606-610.

19. Ahmed AE, Alaskar AS, Mcclish DK, et al. Saudi SCD patients'symptoms and quality of life relative to the number of ED visits. BMC Emerg Med. 2016;16(1):30.

20. Sabik LM, Cunningham PJ, Tehrani AB. Changes in emergency department utilization after early Medicaid expansion in California. Med Care. 2017;55(6):576-582.

21. Rust G, Zhang S, Reynolds J. Inhaled corticosteroid adherence and emergency department utilization among Medicaid-enrolled children with asthma. Journal of Asthma. 2013 Sep 1;50(7):769-775.

22. Cheung PT, Wiler JL, Lowe RA, Ginde AA. National study of barriers to timely primary care and emergency department utilization among Medicaid beneficiaries. Ann Emerg Med. 2012;60(1):4-10.

23. Schoenfeld EM, Mckay MP. Weekend emergency department visits in Nebraska: higher utilization, lower acuity. J Emerg Med. 2010; 38(4):542-545. 
Therapeutics and Clinical Risk Management

Dovepress

\section{Publish your work in this journal}

Therapeutics and Clinical Risk Management is an international, peerreviewed journal of clinical therapeutics and risk management, focusing on concise rapid reporting of clinical studies in all therapeutic areas, outcomes, safety, and programs for the effective, safe, and sustained use of medicines. This journal is indexed on PubMed Central, CAS,

EMBase, Scopus and the Elsevier Bibliographic databases. The manuscript management system is completely online and includes a very quick and fair peer-review system, which is all easy to use. Visit $\mathrm{http}: / / \mathrm{www}$.dovepress.com/testimonials.php to read real quotes from published authors.

Submit your manuscript here: http://www.dovepress.com/therapeutics-and-clinical-risk-management-journal 